\title{
Pengaruh Suhu, Kadar Garam dan Waktu Pengolahan Bakasang Ikan Cakalang (Katsuwonus pelamis) Terhadap Parameter Thiobarbituric Acid (TBA) \\ (The Influence of Temperature, Salinity and Processing Time of Bakasang Cakalang Fish (Katsuwonus pelamis) on Thiobarbituric Acid (TBA) Parameters)
}

\author{
Jessica Marcelina Tungady ${ }^{1)}$, Feti Fatimah ${ }^{1)}$, Vanda Kamu ${ }^{1)}$ \\ 1) Jurusan Kimia FMIPA Universitas Sam Ratulangi \\ ${ }^{\star}$ Email korespondensi: tungadyjessica@gmail.com
}

Diterima 1 Juli 2019, diterima untuk dipublikasi 5 Agustus 2019

\begin{abstract}
Abstrak
Bakasang adalah produk fermentasi yang dibuat dari jeroan ikan. Penelitian ini bertujuan menganalisis pengaruh suhu, kadar garam dan waktu terhadap pengolahan bakasang ikan Cakalang (Katsuwonus pelamis) dibuat dengan berbagai kondisi pengolahan. Analisis menggunakan parameter Thiobarbituric acid (TBA) pada setiap sampel. Hasil menunjukan bilangan TBA tertinggi yaitu dengan suhu $70^{\circ} \mathrm{C}$, kadar garam 30\% dan waktu fermentasi selama 15 hari dengan bilangan TBA sebesar 4,7439 mg malonaldehid/kg sampel dan bilangan TBA terendah yaitu yaitu dengan suhu $50^{\circ} \mathrm{C}$, kadar garam $20 \%$ dan waktu fermentasi 1,6 hari dengan bilangan TBA sebesar 0,9709 mg malonaldehid/kg sampel. Tujuan dari penelitian ini adalah untuk menentukan pengaruh suhu, kadar garam dan waktu pengolahan (variabel independen) terhadap parameter Thiobarbituric acid (TBA) (variabel dependen), maka diperlukan beberapa metode statistika, pertama yaitu uji korelasi suhu, kadar garam dan waktu (variabel independen) terhadap bilangan Thiobarbituric acid (TBA) (variabel dependen) dengan hasil penelitian, berturut-turut 56,4\%; 28,3\%; dan 60,7\%, selanjutnya adalah uji ANOVA, analisis varians (ANOVA) dilakukan pada $95 \%$ confidence interval dengan nilai signifikansi $\alpha=0,05$, hasil signifikansi untuk variabel suhu, kadar garam dan waktu adalah 0.00 .
\end{abstract}

Kata Kunci: Bakasang, ikan Cakalang, ANOVA, bilangan TBA

\begin{abstract}
Bakasang is a fermented product made from fish innards. In this research, aims to determine the effect of temperature, salinity and time on the processing a bakasang of Cakalang (Katsuwonus pelamis) made with various processing conditions a bakasang of Cakalang fish (Katsuwonus pelamis) was made with various processing conditions. The analysis was carried out using Thiobarbituric acid (TBA) parameters in each sample. Based on the research, the highest TBA number is at $70^{\circ} \mathrm{C}, 30 \%$ salinity and fermentation time for 15 days with TBA number of 4,7439 $\mathrm{mg}$ malonaldehyde $/ \mathrm{kg}$ sample and the lowest TBA number that is with a temperature of $50^{\circ} \mathrm{C}$, salt content $20 \%$ and time 1,6 day fermentation with TBA number of 0,9709 $\mathrm{mg}$ malonaldehyde $/ \mathrm{kg}$ sample. The aim of this research is to determine the effect of temperature, salinity and processing time (independent variables) on the parameters Thiobarbituric acid (TBA) (dependent variable), then some statistical methods are needed, first, the correlation test of temperature, salt content and time (independent variable) on Thiobarbituric acid (TBA) number (dependent variable) with the results of research, respectively 56,4\%; 28,3\%; and 60,7\%, next is the ANOVA test, analysis of variance (ANOVA) was carried out at $95 \%$ confidence intervals with a significance value of $\alpha=0,05$, variable significance for temperature, salinity and time was 0,00.

Keywords: Bakasang, Cakalang fish, ANOVA, TBA number
\end{abstract}




\section{PENDAHULUAN}

Potensi sumberdaya alam wilayah pesisir dan laut Provinsi Sulawesi Utara yang di dalamnya terkandung sumberdaya alam hayati, mempunyai prospek yang baik untuk dikembangkan dalam rangka menunjang pembangunan daerah. Sumberdaya hayati tersebut terdiri dari berbagai jenis ikan. Produksi perikanan pelagis di Sulawesi Utara pada tahun 2011 didominasi oleh jenis ikan Cakalang (Katsuwonus pelamis), dengan produksi sebesar $60.158,8$ ton $(26,05 \%$ dari total produksi perikanan tangkap Sulut) (Anonim 2011).

Ikan jenis ini banyak diolah oleh masyarakat menjadi bahan ekspor dengan memanfaatkan dagingnya sebagai buah tangan tradisional seperti abon dan Cakalang fufu, sedangkan sisa olahan dari ikan cakalang berupa jeroan (usus, lambung, hati, jantung dan telur) tidak diolah menjadi produk pangan berkualitas, umumnya dibuang dan sebagian dimanfaatkan sebagai produk sampingan. Salah satu dari produk jeroan ikan Cakalang yang sangat digemari oleh masyarakat Sulawesi Utara adalah bakasang (Yempormase et al. 2017).

Bakasang merupakan olahan jeroan ikan Cakalang yang dalam proses pengolahannya dilakukan penambahan garam dengan teknik fermentasi tradisional dan penyimpanan dalam botol dengan bantuan sinar matahari selama beberapa hari yang memungkinkan adanya pemanasan dan mengakibatkan oksidasi, proses oksidasi merupakan reaksi pembentukan radikal terinduksi yang berlangsung menurut tahapan inisiasi, propagasi, dan terminasi. Reaksi ini dipercepat oleh beberapa faktor yaitu suhu (panas), kadar garam dan lamanya waktu, sehingga pengolahan bakasang secara tradisional tersebut kurang efektif (ljong dan Ohta 1995).

Ikan jenis ini banyak diolah oleh masyarakat menjadi bahan ekspor dengan memanfaatkan dagingnya sebagai buah tangan tradisional seperti abon dan Cakalang fufu, sedangkan sisa olahan dari ikan cakalang berupa jeroan (usus, lambung, hati, jantung dan telur) tidak diolah menjadi produk pangan berkualitas, umumnya dibuang dan sebagian dimanfaatkan sebagai produk sampingan. Salah satu dari produk jeroan ikan Cakalang yang sangat digemari oleh masyarakat Sulawesi Utara adalah bakasang (Yempormase et al. 2017).

Bakasang merupakan olahan jeroan ikan Cakalang yang dalam proses pengolahannya dilakukan penambahan garam dengan teknik fermentasi tradisional dan penyimpanan dalam botol dengan bantuan sinar matahari selama beberapa hari yang memungkinkan adanya pemanasan dan mengakibatkan oksidasi, proses oksidasi merupakan reaksi pembentukan radikal terinduksi yang berlangsung menurut tahapan inisiasi, propagasi, dan terminasi. Reaksi ini dipercepat oleh beberapa faktor yaitu suhu (panas), kadar garam dan lamanya waktu, sehingga pengolahan bakasang secara tradisional tersebut kurang efektif (ljong dan Ohta 1995).

Berdasarkan penelitian sebelumnya yang dilakukan oleh Fatimah et al. (2017), kondisi pengolahan berpengaruh terhadap bilangan Thiobarbituric acid (TBA) diantaranya suhu, kadar garam dan waktu. Penelitian ini bertujuan untuk menganalisis pengaruh suhu, kadar garam dan waktu pengolahan bakasang ikan Cakalang (Katsuwonus pelamis) terhadap bilangan Thiobarbituric acid (TBA) 
METODE

\section{Pengolahan Bakasang Ikan Cakalang (Katsuwonus pelamis) (Fatimah et al. 2017)}

Ikan Cakalang segar dipisahkan bagian isi perut dari daging ikan, jeroan (usus, hati, jantung dan telur) ikan dicuci dalam wadah dipotong menjadi bagian-bagian yang lebih kecil, selanjutnya ditiris dalam ayakan, dicampur dengan garam yang bervariasi dengan konsentrasi $(3,18 ; 10 ; 20 ; 30 ; 36,82) \%$ dan dibiarkan berfermentasi dalam fermentor selama $(1,6 ; 5 ; 10 ; 15$; $18,3)$ hari dan pada suhu yang bervariasi $\quad(16,36 ; 30 ; 50 ; 70$; $83,64)^{\circ} \mathrm{C}$.

\section{Thiobarbituric Acid (TBA) (Yanti \& Rochima 2009)}

Pereaksi TBA yang digunakan sebanyak $0,2883 \mathrm{~g}$ dilarutkan dalam $100 \mathrm{~mL}$ asam asetat glasial $90 \%$. Sampel ditimbang sebanyak 10 gram dengan teliti, ditambahkan 50 $\mathrm{mL}$ aquades. Sampel kemudian dipindahkan ke dalam labu destilat sambil dicuci dengan $50 \mathrm{~mL}$ aquades. Nilai $\mathrm{pH}$ diatur menjadi 1,5 dengan menambahkan $\mathrm{HCl} 4 \mathrm{M}$ sebanyak $5 \mathrm{~mL}$. Sampel didestilasi dengan pemanasan tinggi $\left(90^{\circ} \mathrm{C}\right.$ $100^{\circ} \mathrm{C}$ ) hingga diperoleh $15 \mathrm{~mL}$ destilat. Destilat yang diperoleh diaduk secara merata lalu dipipet sebanyak $5 \mathrm{~mL}$ dimasukkan ke dalam tabung reaksi, kemudian ditambahkan $5 \mathrm{~mL}$ pereaksi TBA, ditutup dan dicampurkan hingga merata. Larutan selanjutnya dipanaskan selama 35 menit dalam air mendidih. Untuk blanko dibuat dengan menggunakan $5 \mathrm{~mL}$ aquades dan $5 \mathrm{~mL}$ pereaksi TBA dan diperlakukan sama dengan sampel. Tabung reaksi didinginkan dengan air dingin selama 10 menit, kemudian diukur absorbansinya (D) pada panjang gelombang $528 \mathrm{~nm}$ dengan larutan blanko sebagai titik nol.
Nilai TBA dapat dihitung dengan persamaan :

$$
\begin{aligned}
& \text { Bilangan TBA } \\
& =\frac{7,8 \times D \times 3}{\text { bobot sample }(\text { gram })}
\end{aligned}
$$

Keterangan:

D = Nilai absorbansi sampel

pada panjang gelombang $528 \mathrm{~nm}$

$7,8=$ Bilangan TBA mg

malonaldehid $/ \mathrm{kg}$ sampel

$3=$ Bilangan iod merupakan derajat ketidakjenuhan lemak/minyak sebagai jumlah gram iod yang diserap oleh 100 gram minyak/lemak.

Analisis data digunakan untuk mencapai hasil penelitian yang komprehensif pertama yaitu uji korelasi antar variabel independen terhadap bilangan Thiobarbituric acid (TBA), selanjutnya adalah uji ANOVA yang digunakan untuk menguji signifikansi variabel yang berpengaruh pada proses pengolahan baksang ikan Cakalang (Katsuwonus pelamis). Analisis varians (ANOVA) dilakukan pada 95\% confidence interval (Lazic 2004).

\section{HASIL DAN PEMBAHASAN}

Berdasarkan hasil pengujian TBA bakasang ikan Cakalang, yang memiliki bilangan TBA tertinggi yaitu dengan suhu $70^{\circ} \mathrm{C}$, kadar garam $30 \%$ dan waktu fermentasi selama 15 hari dengan bilangan TBA sebesar 4,7439 mg malonaldehid/kg sampel. Sebaliknya, bilangan TBA terendah yaitu dengan suhu $50^{\circ} \mathrm{C}$, kadar garam $20 \%$ dan waktu fermentasi 1,6 hari dengan bilangan TBA sebesar 0,9709 mg malonaldehid/kg sampel (Tabel 1).

Menurut Boran et al. (2006), bilangan TBA yang baik untuk minyak ikan adalah sebesar 7-8 mg malonaldehid $/ \mathrm{kg}$ sampel. Berdasarkan pernyataan tersebut, dengan demikian dapat disimpulkan bahwa bakasang ikan Cakalang 
dengan suhu, kadar garam dan waktu fermentasi dengan berbagai kondisi pengolahan sesuai dengan Tabel 1. masih dalam taraf aman karena tidak melebihi standar yang ditetapkan.

Tabel 1. Hasil analisis bilangan Thiobarbituric acid (TBA) dengan berbagai kondisi pengolahan

\begin{tabular}{cccc}
\hline $\begin{array}{c}\text { Suhu } \\
\left({ }^{\circ} \mathrm{C}\right)\end{array}$ & $\begin{array}{c}\text { Kadar } \\
\text { Garam } \\
(\%)\end{array}$ & $\begin{array}{c}\text { Waktu } \\
(\text { Hari })\end{array}$ & $\begin{array}{c}\text { Bilangan TBA } \\
(\mathrm{mg} \\
\text { malonaldehid } / \\
\text { kg sampel) }\end{array}$ \\
\hline 30 & 10 & 5 & 1,5639 \\
70 & 10 & 5 & 2,9132 \\
30 & 30 & 5 & 2,22005 \\
70 & 30 & 5 & 3,2568 \\
30 & 10 & 15 & 3,0469 \\
70 & 10 & 15 & 4,3995 \\
30 & 30 & 15 & 3,6361 \\
70 & 30 & 15 & 4,7439 \\
16,3641 & 20 & 10 & 1,3069 \\
83,6359 & 20 & 10 & 4,5424 \\
50 & 3,1821 & 10 & 1,1852 \\
50 & 36,8179 & 10 & 3,1001 \\
50 & 20 & 1,591 & 0,9709 \\
50 & 20 & 18,409 & 4,0616 \\
50 & 20 & 10 & 2,1744 \\
50 & 20 & 10 & 2,1777 \\
50 & 20 & 10 & 2,1405 \\
50 & 20 & 10 & 2,1254 \\
50 & 20 & 10 & 2,0905 \\
50 & 20 & 10 & 2,2294 \\
\hline & & & \\
\hline
\end{tabular}

Uji Korelasi antar variabel (suhu, kadar garam dan waktu) terhadap Bilangan Thiobarbituric acid (TBA)

Analisis kolerasi mencoba mengukur kekuatan hubungan antara dua variabel melalui sebuah bilangan yang disebut koefisien kolerasi. Menurut Walpole (1996), koefisien korelasi merupakan ukuran hubungan linier antara dua peubah $\mathrm{x}$ dan $y$, yang disimbolkan dengan " $r$ ". Dilakukan uji korelasi untuk mengetahui tingkat hubungan pengaruh masing-masing variabel suhu, kadar garam dan waktu. Nilai korelasi antar variabel diperoleh dari hubungan linear $x$ yang berupa suhu, kadar garam dan waktu terhadap nilai y yang berupa hasil bilangan TBA. Koefisien korelasi mempunyai kisaran nilai antara "-1" (hubungan linier sempurna negatif), "0" (tidak ada hubungan dalam variabel) serta "1" (hubungan linier sempurna positif). Bila $r$ mendekati + 1 atau -1, hubungan antara kedua variabel kuat dan terdapat korelasi yang tinggi antara keduanya. Akan tetapi, bila $r$ mendekati nol hubungan antar variabel sangat lemah atau mungkin tidak ada sama sekali. Notasi (+) dan (-) menunjukkan hubungan searah atau lurus dan berlawanan arah atau berbanding terbalik. Hasil uji korelasi antara variabel suhu, kadar garam dan waktu terhadap bilangan TBA (Tabel 2.)

Tabel 2. Korelasi tiga variabel proses terhadap bilangan TBA

\begin{tabular}{cc}
\hline Variabel $(\mathrm{x})$ & Nilai koefisien $(\mathrm{r})$ \\
\hline Suhu & $0,564^{\star \star}$ \\
Kadar garam & 0,283 \\
Waktu & $0,607^{\star \star}$ \\
\hline
\end{tabular}

Keterangan: **Menunjukkan terdapatnya kekuatan korelasi variabel terhadap respon.

Dapat dilihat bahwa waktu, nilai korelasinya adalah $0,607^{* *}$, dan suhu nilai korelasinya adalah $0,564^{* *}$, sedangkan kadar garam nilai korelasinya adalah 0,283 . Sugiyono (2013), menyatakan bahwa korelasi memiliki 5 tingkatan yaitu $0,00<r \leq$ 0,19 (sangat lemah), $0,20<r \leq 0,39$ (lemah), $0,40<r \leq 0,59$ (cukup kuat), $0,60<r \leq 0,79$ (kuat), $0,80<r$ $\leq 1,00$ (sangat kuat).

Tabel 2. menunjukkan bahwa waktu pengolahan atau fermentasi bakasang mempunyai korelasi paling tinggi di antara variabel lainnya yang mengartikan bahwa waktu pengolahan bakasang sangat berpengaruh pada penentuan bilangan TBA. Tingkat korelasi dua variabel dapat dilihat dari tanda ** 
pada variabel yang dikorelasikan.

Pada nilai korelasi waktu pengolahan bakasang memiliki tingkatan korelasi yang kuat.

Winarno (1992), menyatakan bahwa peningkatan bilangan TBA (Thiobarbituric acid) selama penyimpanan disebabkan karena terjadinya kerusakan lemak yang menyebabkan timbulnya bau dan rasa tengik akibat reaksi oksidasi. Hal ini terjadi karena terurainya lipid menjadi peroksida dan selanjutnya menjadi aldehid yang merupakan hasil pemecahan hidroperoksida menjadi malonaldehid.

Pada suhu pengolahan bakasang juga memberikan korelasi yang cukup kuat terhadap bilangan TBA, artinya suhu pengolahan bakasang yang tinggi menyebabkan bilangan Thiobarbituric acid (TBA) naik. Hasan et al. (2014), menyatakan oksidasi berjalan dengan cepat jika suhu penyimpanan cukup tinggi, terkena sinar matahari dan ada tidaknya pemberian antioksidan.

Pada kadar garam memberikan korelasi yang lemah terhadap bilangan TBA, walaupun memberikan korelasi yang lemah, kadar garam memberikan korelasi positif terhadap bilangan Thiobarbituric acid (TBA), artinya ketiga variabel tersebut memberikan pengaruh terhadap pengolahan bakasang dengan menggunakan parameter Thiobarbituric acid (TBA). Belitz dan Grosch (1987), menyatakan reaksi oksidasi dipercepat oleh beberapa beberapa faktor, salah satunya adalah logam transisi, kandungan Timbal (Pb), Tembaga $(\mathrm{Cu})$ yang terkandung dalam garam mempercepat oksidasi, menurut standar SNI 013556-2000, kadar Timbal (Pb) dan
Tembaga (Cu) maksimum $10 \mathrm{mg} / \mathrm{Kg}$ dalam garam dapur.

\section{Uji Signifikansi}

Test of Between-Subjects

Effects, Fhitung masing-masing variabel lebih besar daripada Ftabel $(3,59)$ dimana suhu mempunyai Fhitung> Ftabel $(1294,020>3,59)$. Demikian juga untuk kadar garam dan waktu masing-masing mempunyai Fhitung 328,786 dan 1326,237. Dari hipotesis diatas, maka HO tidak diterima. Hal ini menunjukkan adanya pengaruh antara ketiga variabel terhadap bilangan Thiobarbituric acid (TBA) (Tabel 3.)

Tabel 3. Hasil pengujian ANOVA Thiobarbituric acid (TBA)

\begin{tabular}{|c|c|c|c|}
\hline Sumber & $\mathrm{Df}$ & $\mathrm{F}$ & Sig \\
\hline Model & 1 & 745,474 & 0,00 \\
\hline koreksi & 4 & & 0 \\
\hline Intersep & 1 & $\begin{array}{c}37812,82 \\
8\end{array}$ & $\begin{array}{c}0,00 \\
0\end{array}$ \\
\hline Suhu & 3 & 1294,020 & $\begin{array}{c}0,00 \\
0\end{array}$ \\
\hline $\begin{array}{l}\text { Kadar } \\
\text { Garam }\end{array}$ & 3 & 328,786 & $\begin{array}{c}0,00 \\
0\end{array}$ \\
\hline Waktu & 3 & 1326,237 & $\begin{array}{c}0,00 \\
0\end{array}$ \\
\hline $\begin{array}{l}\text { Suhu*Kadar } \\
\text { garam }\end{array}$ & 1 & 16,634 & $\begin{array}{c}0,01 \\
0\end{array}$ \\
\hline Suhu*Waktu & 1 & 0,298 & $\begin{array}{c}0,60 \\
9\end{array}$ \\
\hline $\begin{array}{l}\text { Kadar } \\
\text { garamWakt } \\
\text { u }\end{array}$ & 1 & 0,233 & $\begin{array}{c}0,65 \\
0\end{array}$ \\
\hline $\begin{array}{l}\text { Suhu*Kadar } \\
\text { garam*Wakt } \\
\text { u }\end{array}$ & 1 & 0,245 & $\begin{array}{c}0,64 \\
2\end{array}$ \\
\hline Eror & 5 & & \\
\hline Total & $\begin{array}{l}2 \\
0\end{array}$ & & \\
\hline $\begin{array}{l}\text { Total } \\
\text { dikoreksi }\end{array}$ & $\begin{array}{l}1 \\
9\end{array}$ & & \\
\hline
\end{tabular}

Pengujian ANOVA dilakukan dengan uji $F$ atau distribusi data. Menurut Arikunto (2001), untuk uji F, dirumuskan hipotesis: $\mathrm{H}_{0}$ : tidak ada pengaruh variabel independen 
terhadap bilangan Thiobarbituric acid (TBA) dan $\mathrm{H}_{1}$ : terdapat pengaruh variabel independen terhadap bilangan Thiobarbituric acid (TBA). Nilai signifikansi pada Tabel 3 untuk variabel suhu, kadar garam dan waktu adalah 0,000, maka baik suhu, kadar garam dan waktu mempunyai pengaruh signifikan yang besar terhadap bilangan TBA, dengan signifikansi tiga variabel $<0,05$. Pengujian signifikansi ini membuktikan bahwa bilangan TBA sangat dipengaruhi oleh ketiga variabel ini.

$R$ square $\left(R^{2}\right)$ atau kuadrat $R$ menunjukkan koefisien determinasi, berkisar antara 0-1. Semakin kecil $\mathrm{R}^{2}$ hubungan antara variabel semakin lemah, sebaliknya jika $R^{2}$ semakin mendekati 1, maka hubungan antara variabel semakin kuat. Angka ini akan diubah kedalam bentuk \% untuk mempermudah penentuan besar kecilnya pengaruh variabel, yang berarti persentase sumbangan pengaruh variabel independen terhadap variabel dependen. Dari tabel, nilai $R^{2}$ sebesar 1,000 artinya sumbangan pengaruh suhu, kadar garam dan waktu terhadap bilangan TBA sebesar $100 \%$, dan model atau variabel independen ini benar-benar sempurna, artinya tidak ada pengaruh oleh variabel lain yang dimasukkan dalam model atau variabel independen tersebut (Setiaji, 2008).

Terlihat pada Tabel 3 adjusted Rsquare merupakan $\mathrm{R}$ yang sudah disesuaikan sebesar 0,998. Angka ini juga menunjukkan pengaruh variabel independen terhadap variabel dependen. $R^{2}$ disesuaikan biasanya untuk mengukur sumbangan pengaruh jika digunakan lebih dari dua variabel.

\section{KESIMPULAN}

Pengolahan bakasang ikan Cakalang (Katsuwonus pelamis) ketiga variabel memberikan pengaruh terhadap bilangan Thiobarbituric acid (TBA) Variasi suhu memberikan pengaruh sebesar $56,4 \%$, variabel kadar garam memberikan pengaruh sebesar $28,3 \%$ dan waktu memberikan pengaruh sebesar 60,7\%. Nilai signifikansi untuk variabel suhu, kadar garam dan waktu adalah 0,000 , maka baik suhu, kadar garam dan waktu mempunyai pengaruh signifikan yang besar terhadap bilangan TBA, dengan signifikansi tiga variabel $<0,05$, pengujian signifikansi ini membuktikan bahwa bilangan TBA sangat dipengaruhi oleh ketiga variabel ini.

\section{DAFTAR PUSTAKA}

Anonim (2011) Dinas Kelautan dan Perikanan Provinsi Sulawesi Utara. 2012. Statistik Perikanan Tangkap Sulawesi Utara.

Arikunto S (2001) Dasar-dasar evaluasi Pendidikan (edisi revisi). Bumi Aksara, Jakarta.

Belitz HD, Grosch (1987) Food Chemistry. Berlin Heidelberg, Springer.

Boran G, Karach, Boran M (2006) Changes in the quality of fish oils to storage temperature and time. Food Chemistry 94(4) : $693-698$.

Dewan Standarisasi Nasional-DSN. 2000. Standar Nasional Indonesia No 01-3556-2000 Garam konsumsi beryodium. SNI, Jakarta.

Fatimah F, Pelealu JJ, Gugule S, Yempormase HV, Tallei TE (2017) Quality evaluation of bakasang processed with variation of salt concentration, temperature and fermentation time. Pakistan Journal of Biological Sciences 20(11): 543551, ISSN 18125735, 10288880.

Hasan B, Iriani D, Densi A (2014) Pengaruh penambahan enzim visceral terhadap pematangan peda ikan kembung (Rastrelliger 
sp). Jurnal Teknologi Hasil Perikanan 1(1): 1-9.

ljong FG, Ohta, Y (1995) Amino acid composition of bakasang, a Traditional fermented fish sauce from Indonesia. Journal of Microbiological Methods 25 (1): 236-237.

Lazic, ZR (2004) Design of experiments in chemical engineering, 481-502. Wiley$\mathrm{VCH}$ Verlag GmbH \& Co. KgaA, Weinheim.
Setiaji, B (2008) Metode penelitian kuantitatif dan kualitatif. UNS Press, Surakarta.

Sugiyono (2013) Metode penelitian pendidikan pendekatan kuantitatif, kualitatif, dan R\&D. Alfabeta, Bandung.

Yanti, AR, Rochima E (2009) Pengaruh suhu pengeringan terhadap karakteristik kimiawi filet lele dumbo asap cair pada penyimpanan suhu ruang. Jurnal Bionatura 11: 21-36. 